\title{
Viaje a Finlandia
}

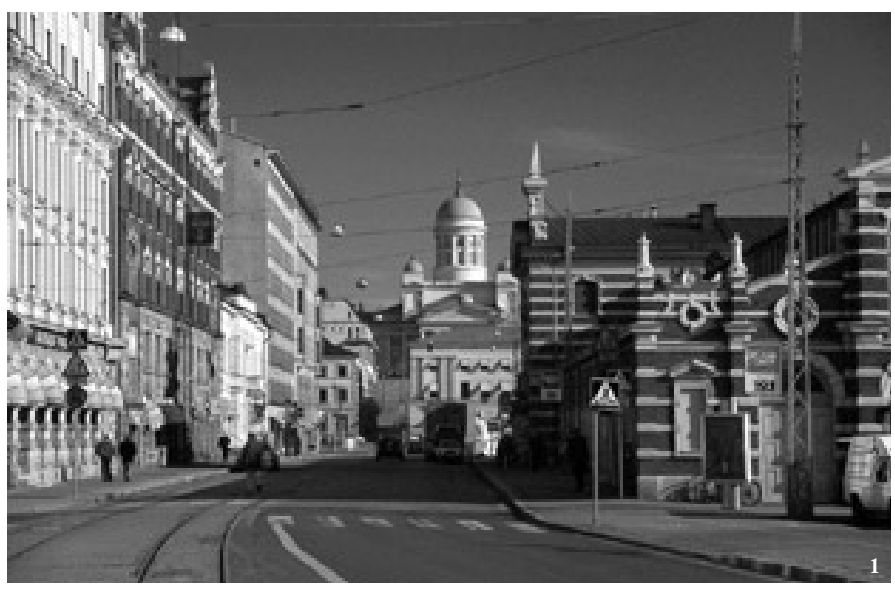

Motivado básicamente por el deseo de visitar la obra del arquitecto Alvar Aalto el autor bizo un viaje por Finlandia. Un país que puede ser considerado una periferia dentro de la periferia, pero que desde esta situación "de borde" -familiar para un cbileno-, en una geografía desmembrada y ondulante y bajo la luminosidad extrema de las latitudes polares ba originado una arquitectura apropiada y razonable.

The desire of visiting Aalto's work impels the author to go to Finland. A country that can be considered a periphery inside the periphery: from its situation "of border" -that is familiar for a Cbilean-, with dismembered and undulant geography and under the extreme brightness and darkness of polar latitudes, it has originated an appropriate and reasonable architecture.

Hace ya un par de años mi amigo y socio Francisco Donoso y yo decidimos hacer un viaje a Escandinavia aprovechando un Eurailpass que ya habíamos comprado, y del que nos sobraba una cantidad considerable de trayectos aún sin utilizar. En realidad, este viaje fue más bien la extensión de otro bastante más largo por Europa (con mochila, alojando en hostales y albergues) que ya estaba llegando a su fin, y que arrojó como balance final varias decenas de rollos de fotos, croqueras llenas de esquemas y dibujos, billeteras casi vacías y un cansancio que pesaba más que la mochila (lo que es bastante decir). La idea principal era la de llegar a Finlandia, interés que estaba motivado básicamente por el deseo de visitar la obra del arquitecto finlandés Alvar Aalto (1898-1976).

Al llegar a Helsinki llevábamos ya un buen tiempo en tierras del Norte, por lo que comenzábamos a acostumbrarnos a que los turistas no son tan habituales en esas latitudes como en otras partes de Europa. De hecho, y aún siendo el mes de abril (menos frío que los propiamente invernales), tengo pocos recuerdos de habernos topado con otros en el mismo plan de dolce far niente en el que estábamos nosotros. Finlandia nos dio, desde los primeros pasos luego de desembarcar del crucero que nos llevó hasta ahí, la impresión de haber dejado atrás Europa para introducirnos en algo mucho más complejo. Las caras no son típicamente nórdicas. Rubias, claro está, pero se adivina algo ancestral que no tiene nada que ver con sus vecinos. El idioma, por cierto, no se parece en nada al danés o al sueco, y está, de hecho, emparentado con el húngaro (vienen de una misma familia, la ugrofinesa) y pertenece junto al turco al grupo de lenguas uraloaltaicas. Había aquí algo asiático, escandinavo, ruso y lapón que forman, en conjunto, un país amable, rotundo como su paisaje y sofisticado culturalmente al mismo tiempo.

De alguna forma Finlandia es una periferia dentro de la periferia: aun dentro del exclusivo círculo de países nórdicos, esta nación es una especie única, y esa imprecisión la hace atractiva. Esta situación "de borde" es familiar para un chileno, aún haciendo la salvedad de los US\$20.000 de ingreso per cápita que nos separan. El país, con una población parecida a la de Santiago, ha logrado hacer de sus desventajas sus mejores aliados. Ante el aislamiento, desarrollaron una industria de telefonía a nivel mundial; ante la geografía desmembrada y ondulante, una inspiración para el diseño; ante el clima difícil, una arquitectura apropiada y razonable.

Helsinki es una ciudad de poco más de medio millón de habitantes. Su emplazamiento es espectacular: se ubica sobre una península que termina desmembrándose en una multitud de pequeñas islas (muchas de ellas habitadas) que prácticamente "proyectan" la ciudad hacia el Báltico. La ciudad es, además, considerablemente nueva (acaba de cumplir 450 años), y es la capital del país sólo a partir del siglo XIX.

El mar es omnipresente, en la comida, en el paisaje, en el clima (gracias a Dios) y en la cultura. Un gran parque la divide en sentido Norte Sur (el Keskuspuisto), lo que, en conjunto con el litoral, le dan un ambiente en el que la sensación de estar en una ciudad está permanentemente en duda. Nada es completamente rural ni completamente urbano, salvo en el casco histórico. No por nada Finlandia es el país europeo con mayor porcentaje de teletrabajadores: estando ahí parece absolutamente obvio que el trabajo desde la casa se adapta perfectamente al modo en que se ocupa el territorio. Dispersión, completa integración al paisaje, predominio de lo natural sobre lo construido, pequeñez frente a lo vasto y abierto: esa es la percepción que queda con el tiempo. La primera impresión de la ciudad de Helsinki corre por cuenta del arquitecto Carl Ludvig Engel que diseñó una buena parte de su centro histórico en estilo Neoclásico, y que le da, al menos en esta zona, una notable continuidad al tejido urbano. Aun cuando estamos lejos de los máximos exponentes del período en otros países más meridionales, esta zona es un compendio de edificios que, sin grandes pretensiones formales, definen una fachada bloque simple y elegante. Tal vez el edificio más representativo de esta idea de ciudad decimonónica sea la Catedral Luterana en la Plaza del Senado, que es la encargada, por su ubicación, de dar la bienvenida a las masas que descienden de los cruceros que atraviesan el Báltico. En esta misma plaza (que es de hecho el lugar de referencia obligado de cualquier turista, el punto de partida y llegada de todos los circuitos) están la Universidad de Helsinki y el edificio del Senado. En el centro de este espacio público, una estatua del zar Alejandro II recuerda la época de esplendor del control ruso sobre el país. Nos habían comentado que las escaleras que conducen a la catedral son el lugar de reunión de la juventud local (a la manera de la Plaza España en Roma), cosa que no pudimos comprobar porque el clima no hacía nada aconsejable una estadía muy prolongada al aire libre (ni siquiera para ellos, mucho menos para nosotros).

En el dominio del skyline de la ciudad la Catedral Luterana debe disputarse la supremacía con la Catedral Uspenski (ortodoxa), una muestra interesante de la presencia rusa. Sus cúpulas doradas contrastan fuertemente con el blanco-amarillo que domina casi todo el resto de la edificación. Para completar el paisaje de la arquitectura religiosa de la ciudad, sólo queda por mencionar la sorprendente Iglesia Temppeliaukio o Iglesia en la 

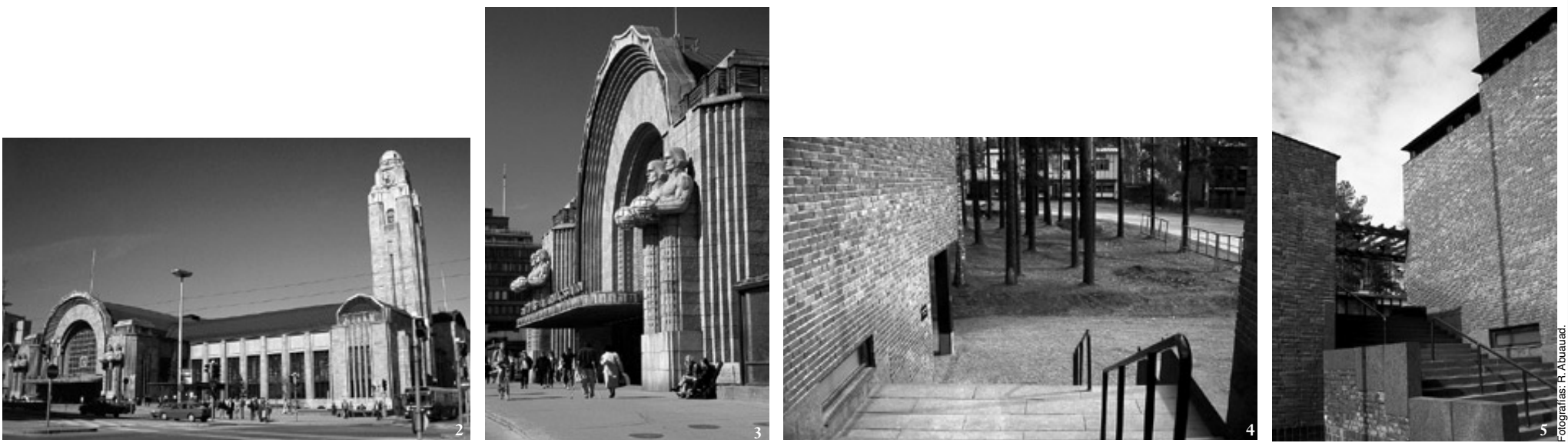

Roca. Terminada en 1969, y obra de Timo y Tuomo Suomalainen, es una verdadera joyita excavada en el granito, iluminada cenitalmente, con absoluta ausencia de elementos superfluos.

Cuando el estilo Neoclásico que impone Engel comienza a agotar sus recursos, un grupo de arquitectos finlandeses decide buscar nuevos horizontes, y traen con fuerza las ideas que imperan en otros países, particularmente Alemania con su propuesta de un Jugendstil, o "estilo de la juventud". Bastante homologable al Art Nouveau, importantes creadores de la talla de Eliel Saarinen deciden cambiar el perfil de Helsinki proyectando edificios con una nueva fuerza expresiva. Dentro de esta idea, lo más significativo es la Estación de Ferrocarriles, obra de este último, una pieza maestra del trabajo del ladrillo, con enormes y casi intimidantes estatuas en el acceso. Se revela aquí una potencia nueva que cambiaría para siempre la relación con el material.

El primer edificio de Aalto que visitamos fue la Casa de la Cultura de 1958, una gran sala de conciertos y eventos, cuya imagen exterior, de ladrillo, es el reflejo del funcionamiento interior. La sala es simple y contemporánea. Habiendo visto mil veces las plantas en forma de abanico de Aalto, teníamos la curiosidad de saber cómo operan en la realidad. En este caso el dinamismo de los planos está completamente reflejado en la obra. La transición entre el acceso y el hall, y entre el hall y la sala se realiza en forma fluida, alejada de la idea de espacios "estancos".

La misma impresión deja el Palacio de Congresos (el Finlandiatalo), cuyo proyecto data de 1962. En este caso, su situación en frente al Töölönlahti (lago en el centro de la ciudad), nos ofreció uno de los espectáculos más interesantes, que sin duda fue considerado en el diseño del edificio: el agua congelada formaba masas blancas que eran repetidas por la silueta angulosa y quebrada de la fachada, revestida en mármol. De nuevo aquí el interior resulta sorprendente por su contemporaneidad. En un día de recorrido que dedicamos exclusivamente a visitar la obra de este arquitecto en la periferia de la capital, estuvimos en varios edificios de diferente escala, dentro de los cuales cabe mencionar la casa del arquitecto y la Universidad de Otaniemi, de 1955. Un programa mil veces visto y recreado (una casa de estudios con sus distintos recintos), es llevado a una interpretación completamente nueva, como la manera en que el gran auditorio tiene sentido no sólo por dentro sino también desde el exterior (su pendiente se utiliza como graderías hacia el parque).

Después de recorrer algunas otras obras del arquitecto en Helsinki, como la librería universitaria, tomamos un tren con destino a la ciudad de Jyvaskylä. El viaje fue considerablemente largo, y se justificaba principalmente por la existencia ahí de una importante cantidad de edificios de Aalto. Particularmente interesante es el centro administrativo y cultural de la ciudad, cuyo proyecto data de 1964, con la característica forma en abanico de su sala mayor. También nos encontramos aquí con una sorpresa, el Museo Alvar Aalto, de 1971, una muestra completa de su obra arquitectónica y de diseño. Jyvaskylä está en realidad plagada del legado arquitectónico de Aalto. Aquí están también una Jefatura de Policía, la universidad Pedagógica, un Centro Deportivo Universitario y una piscina cubierta. Todas tienen indiscutiblemente su sello. En la medida en que se aleja uno de Helsinki, cada vez es más intensa la impresión de que la obra de Aalto está pensada para el paisaje de Finlandia: en estas ciudades pequeñas, en que la presencia de lo verde, lo vasto, del cielo rasante, es mucho mayor que en la capital, el edificio se revela aún más apropiado, porque está pensado para ello.

Sin embargo, nada de lo que vimos ahí nos impresionó de la manera que lo hizo el ayuntamiento de la ciudad cercana de Säynätsalo. Muchas veces dibujado y visto en cuanta publicación se ha hecho sobre este arquitecto, corríamos el riesgo, como ocurre con frecuencia, de que las imágenes del proyecto fueran mejores que la realidad. No es el caso. Para los no arquitectos el nombre puede no decir nada, pero es imposible pasar por una carrera como ésta y no haber intentado al menos una vez en un proyecto hacer un acceso "a la manera de" Säynätsalo. Nada que hubiéramos visto le hace justicia a la manera en que el edificio y el bosque son prácticamente uno. Estuvimos ahí mucho rato. Esa sola obra basta para entender por qué se considera a su autor como un maestro del siglo XX. Aún si Aalto no hubiese construido más que esto, bastaría para considerarlo un genio.

Después de bastantes dudas por la distancia a la que quedaba, decidimos emprender la última parte del viaje hacia Seinäjoki. Lograr que el tipo que vendía los boletos de tren entendiera hacia qué lugar queríamos ir fue una proeza que requirió de todo nuestro talento (de hecho, no hubo caso hasta que no se lo indicamos en un plano). Si se quiere comprender la visión urbana de Aalto, ese es el lugar. Su centro cívico es completamente su obra, y se encuentran ahí algunos de sus proyectos más conocidos, como la biblioteca (1965), el teatro (1987), el ayuntamiento (1962) y la iglesia (1960). ¿Cuál es la impresión general de un paisaje íntegramente aaltiano? La respuesta no puede separarse del contexto geográfico: entender el centro cívico de Seinäjoki es también entender cómo el arquitecto propone integrarse al lugar. Volúmenes angulosos blancos y negros emergen de la explanada cubierta de nieve gran parte del año. La sensación es que en ese espacio se guarda y recrea la quietud propia de la taiga finlandesa. La vuelta se hizo larga, pero el tren de alguna manera permite pensar sin el cargo de conciencia de estar perdiendo tiempo valioso. Permite ordenar los apuntes y los croquis. La sensación es la de estar terminando un viaje que posiblemente no se repita, por lo lejos y lo específico de nuestro interés. ¿Qué imagen queda? La de un país refinado estéticamente en el que este arquitecto no se comprende como un ente aislado sino como parte de una sensibilidad especial. La fascinación por la pureza de formas y el diseño aparece como una constante escandinava, y especialmente de Finlandia. La contemplación de esos paisajes de gran fuerza seguramente deja una marca que afecta. Nos afectó a nosotros, y no me cabe duda que los afecta mucho más aún a ellos. ARQ 